\title{
Legal Thoughts on the Development of New Cycle of Shared Bicycle
}

\author{
Dai Yuntian \\ Wuhan University of Technology, Wuhan
}

Email : 270371056@qq.com

\begin{abstract}
Under the background of innovation driven development, Internet technology has changed people's lifestyle. To adapt to the current situation, the sharing of the bike quickly swept the country, it has attracted peoples much attention. This paper first introduce present status of development of the shared bicycle, Therefore, it puts forward the legal issues concerning the supervision, profitability and safety of the bicycles, analyze its problems for various reasons, Finally, it is concluded that the shared bicycle should be regulated by relevant laws and regulations, to clarify and standardize its status, must bring more convenience to the public on the basis of safety supervision. We hope that under the new situation of "Internet plus" some laws and regulations will be introduced as soon as possible for the sharing of bicycles to maximize the legal guarantee for the economic market.
\end{abstract}

Key words: Sharing bike; Legalization; Safety supervision; Legislation regulation

With the rapid development of Internet economy, many new products are springing up like mushrooms, Sharing bicycle is such a new market, come into the life of the citizens. From Beijing to Shenzhen、 from Shanghai to Chengdu, There are about 20 bike sharing companies, In the capital pouring it quickly entered the first, second tier cities to seize the market. Because of the penetration of mobile Internet technology, mobile payment mode and operation mode, let the shared bike get rid of the shackles of traditional parking piles, show its convenience and flexibility[1]. The birth of a shared bike, not only meets the public demand for a large number of short distance travel, but also helps to solve the problems of urban traffic congestion and environmental pollution, what's more ,it is consistent with the "green travel" "healthy China" "public entrepreneurship, innovation" and other development concepts. However, while it brings a variety of positive social effects, Its status should also be recognized and recognized by law, In addition, the security issues of concern to the people also need to be appropriate legislative supervision.

\section{Introduces the development of shared bike}

\subsection{The rise of shared bikes}

Nowadays, a variety of Shared bikes, led by Mo bai and OFO, swept every corner of the city. So far, the national shared bike application software has exceeded thirty. By the end of 2016, China's shared bicycle market as a whole the number of users nearly 19 million. According to the relevant agencies predicted that by the end of 2017, shared bicycle market users will reach 50 million [2].

\subsection{Analysis of the reasons for the rapid development of shared bicycles}

\subsubsection{Maturity of technical application conditions}

With the popularity of smart mobile phones in China, people in most cities can use the Internet to accomplish all kinds of consumption. Therefore, the maturity of technology applications provides the necessary technical support for the rapid development of shared bicycles.

\subsubsection{The great market demand}

Sharing bicycles is essentially a time-sharing lease for bicycles, its features are convenient, environmentally friendly, cost-effective and suitable for short-distance, these advantages are considered by the industry to solve the "last mile" of the weapon, its demand is considerable, As a result, become a necessary means of transportation with public transportation, taxis, Internet buses and so on. 


\section{Problems shared by bicycles}

\subsection{Regulatory and profitability issues}

\subsubsection{Managing confusing puzzles}

The "no-pile" operation model of sharing bikes gives users more convenience, it not only expand the selection of parking spots, but also brought great convenience for the public to solve the "last mile". However, there are still some urgent problems in management, in the actual use of the process, it is difficult to find white frame sign to stop, and it is very common that the public free parking behavior causes the public areas such as sidewalks and bus stations to be occupied. Bring serious inconvenience for more people to return the car, pick up the car[3].

\subsubsection{Its own assets are too heavy and lack of profitability}

For the profit of shared bicycles, generally require the public to advance and pay a deposit of one or two hundred yuan, formed a certain amount of funds precipitation, bring a certain amount of gains to the bicycle company. In the use of bicycles, the public still need to pay a certain fee. However, compared with the huge capital investment, the profitability of sharing bicycles is not enough to show.

\subsection{Questions about rights and obligations}

According to the provisions of the Contract Law, both parties to the contract should exercise their powers and fulfill their obligations in accordance with the contract, specifically, the cycling company has the right to charge a rental fee, but at the same time should also provide quality qualified products, and fulfill the obligations of management and maintenance; at the same time the user who is the counterpart of the contract has the right to use the vehicle, the obligations of the rational use of the vehicle shall also be fulfilled in accordance with the agreed use of the contract. Sharing bicycles to develop is inseparable from the supervision of laws and regulations. Therefore, it is necessary to coordinate the rights and obligations among social administrators, enterprises and ordinary lessees.

\section{Imperfect regulation of sharing bicycle}

\subsection{There is a financial risk in the deposit}

Nowadays, users use OFO first to pay 99 yuan deposit, Mumbai cycle to pay 299 yuan deposit, in addition to recharge, recharge the amount of unrestricted, it can secure a larger income only by deposit fees. According to public information, by the end of last year, the OFO bike market had the largest number of vehicles, up to 800,000 ,Mo bike have 600000 , each car can be used for many people. As a result, the amount of the deposit charged by OFO and the motorbike is expensive. So far, the number of users using bicycles has increased rapidly, and the deposit has been increased by the two companies alone[4]. However, it is worth noting that even if the deposit can be returned in seconds, but the recharge is not refundable, there are still potential legal risks. In the case of individuals without bargaining power, the executive authorities should be clearly regulated. Whether the deposit belongs to disguised financing, which is the financial regulatory authorities need to pay attention to the problem, Its consequences are unpredictable[5].

\subsection{Damage the bike to crack the password}

Due to illegal parking, the problem of shared bike damage arises, and the situation is getting worse. Someone maliciously removed the seat and held it for himself, so that others cannot be used normally. There are people who maliciously crack the password, by using the password or from someone else to get the password to achieve the purpose of free use[6]. From the perspective of civil law, bicycles belong to the object of the three elements of law, damage to the bike is the "material" caused damage, infringement of bicycle ownership of bicycles, as for the blocked license plate number, Although it does not damage the property right of the owner, it affects the owner's income and thus infringes his right of return. 


\section{Sharing the Safety Supervision of Bicycles}

\subsection{Strengthen cooperation with the local government, seeking financial subsidies}

The further development of shared bicycles also requires the support of the local government, through cooperation with local governments, to strengthen the layout and management of non-motor vehicle lanes, to meet the growing demand for shared bicycle. Meanwhile, through the use of big data, with the local government, reasonable layout of bicycle parking spots, to achieve the effective allocation of resources. Besides, shared bicycles can also make up for the short circuit of public transport. Although it is a commercial mode of operation, it covers a large public welfare component, appropriate financial subsidies should be provided by the local government.

\subsection{Speed up the perfect sharing of bicycle system}

Technicians can develop specialized shared bike maps through accurate positioning systems. Besides, for customers who need to use the car, you can clearly mark the number of surrounding bicycles, the specific location and so on; For customers who need to end the car, they should be prompted for the correct parking point around them; For those who do not follow the provisions of the parking, should be given the appropriate punishment. Meanwhile, research the dynamic pricing mechanism through price incentive, allowing users to participate in vehicle scheduling operations, and ultimately can reduce the cost of sharing bike maintenance.

\subsection{Increase the punishment, build the spirit of the contract}

To share bicycle damage, unauthorized possession, illegal parking and other acts, should be bicycle companies jointly with the local police department to increase penalties, and encourage residents to report violations of law. For some violations of the provisions of the bike travel individual, you can appropriately improve the use of its bicycle guarantee amount, it can also increase the cost of its single use of bicycles. Faced with a number of bad behavior, they can be included in the bicycle user blacklist, and can be set up for a period of time prohibit its use of bicycles. Then work closely with local police department[7].

\section{Conclusion}

With the acceleration of China's economic transformation and upgrading, the sharing of bicycles will make continuous progress and development, advance in setbacks, develop in difficulties, seek experience from problems, and seek directions for development. Law comes from social life, but at the same time regulate social life, so only the law that reflects the real life of society is vitality[8]. As China's urbanization process continues to accelerate, in the development will inevitably appear a variety of problems, But I believe that under the powerful macro-control of our government, sharing bicycles will advance in the face of adversity, and under effective system management, towards healthy and good trend forward.

\section{References}

[1] He Ke, Li Hao. How to share a bicycle "ride farther"? [R]. Anhui Daily News, 2017 (2).

[2] Shi Hai'e. Sharing bicycles: 100 billion market to be excavated [J]. Glory, 2017 (2): 46-47.

[3] Liu Xun. Leaving the rule of law, sharing the bike will be unable to move [N]. People's Court reported

[4] Wang Huanming, Li Peng. Urban public bicycle service privatization supply model comparative study [J]. China Soft Science, 2015 (6): 56-66.

[5] Zhou Min. Mabe bicycles duel against theo: shared bicycle "fire" [J]. Shanghai and Hong Kong economy, 2016, (11): 19-24.

[6] Wang Lijuan. Road where the lack of bike where to go [N]. China Reform News, 2017-2-16 (5). 
[7] Wang Zhao-li. Evaluation and management of the car and taxi market under the shared economic model [J] .Enterprise Reform and Management, 2016 (05)

[8] Zhou Li yan. O2O shared economic business model status and development strategy research [J]. China high-tech enterprises, 2016 (24) 